\title{
Approaches to Polymeric Mechanochromic Materials
}

\author{
Céline Calvino", Laura Neumann", Christoph Weder*, Stephen Schrettl* \\ Adolphe Merkle Institute, University of Fribourg, Chemin des Verdiers 4, 1700 Fribourg, Switzerland \\ "These authors contributed equally. \\ *Correspondence to: Christoph Weder (christoph.weder@unifr.ch), Stephen Schrettl \\ (stephen.schrettl@unifr.ch)
}

\begin{abstract}
Mechanochromic materials respond to mechanical stimuli with a change of their optical properties. Such materials are of interest for many technological applications and support fundamental research as they help improving the understanding of stress transfer in polymeric objects and aid in the identification of the processes that lead to mechanical failure. In this highlight, different approaches are discussed that permit the design of polymeric materials, which signal mechanical stresses through a chromic response. This highlight emphasizes materials that exhibit mechanically induced changes of their intrinsic absorption or emission properties. These responses almost exclusively originate from changes of molecular structure, conformational rearrangements, or disruption of intermolecular interactions.
\end{abstract}

KEYWORDS: chromogenic, mechanochromic, polymer, stimuli-responsive, color change

\section{INTRODUCTION}

There is widespread fundamental interest in the development of materials that either reversibly or permanently change their color in response to an external stimulus. ${ }^{1,2}$ Mechanochromic materials, i.e., materials that display an optical response in reaction to the application of a mechanical stimulus, ${ }^{3-7}$ represent an important subset of this class of materials. The ability to selectively and reliably signal mechanical stresses is not only of great fundamental interest, but also potentially useful for technological applications in fields that range from packaging to structural health monitoring. ${ }^{4,7}$ Among the most prominent examples are tamper-proof packaging materials, structural components that help to predict mechanical failure by displaying visual warning signs when elements are highly strained, or stress-sensitive sensors that allow for an in situ signaling of deformation and failure. The visualization of the effects of mechanical stresses on polymeric materials is also useful for developing a deeper understanding of stress transfer in polymeric objects and the underlying processes of mechanical failure. ${ }^{8}$

The optical responses associated with mechanochromic materials can involve changes of the absorption, emission, and reflection of light. ${ }^{9}$ Alterations of the reflectivity are generally the result of mechanical manipulations of defined nanostructures and associated photonic effects. ${ }^{10-12}$ By contrast, mechanically induced modifications of the absorption or emission properties, which are the main subject of this highlight, almost exclusively originate from variations of molecular structure, conformational rearrangements, 
and/or changes of intermolecular interactions. These principles are at play in small molecule compounds that show mechanochromic behavior, as well as in polymeric materials. The former typically take the form of crystalline solids without notable mechanical properties and are, as such, beyond the scope of this highlight. Readers with specific interests in such compounds are directed towards recent review articles. ${ }^{13-16}$

When polymers are placed under mechanical stress, a variety of processes may take place that range from subtle adjustments, such as a reshuffling of the conformation of polymer chains, to chemical reactions, such as the cleavage of covalent chemical bonds, to rearrangements involving multiple molecules. ${ }^{17-22}$ Taking advantage of these processes has allowed researchers to devise a plethora of responsive materials that show a variety of mechanically triggered functions, including catalysis, $\mathrm{pH}$ changes, and healing. ${ }^{17-19}$ If stressinduced physical or chemical rearrangements affect chromogenic moieties, changes of a material's absorption and emission properties may occur. Provided that the spectral changes are significant and that the properties of a sufficiently large fraction of the chromophores in the system are changed, macroscopically detectable mechanochromic responses can be achieved. Whether a mechanochromic response is reversible or permanent usually depends on the reversibility of the physical or chemical changes to the chromogenic moieties. Another important determinant is the deformation behavior of the polymer system under the applied strain or stress, i.e., whether the deformation is elastic or plastic. ${ }^{7}$

The different approaches pursued to design mechanochromic materials can be classified according to the processes that occur upon application of the mechanical stimulus. Conformational changes of polymer chains, the dispersion of dye aggregates embedded in polymer matrices, cleavage of non-covalent interactions, or the scission of covalent bonds are the main mechanisms that have been employed as the basis for the creation of polymer-based mechanochromic materials. In the following, these different approaches are highlighted by means of selected illustrative examples that showcase the general principles at play and we provide an overview of the design principles of mechanochromic materials.

\section{CONFORMATIONAL CHANGES OF POLYMERS}

At the molecular level, polymers react to tensile deformation by extending through stretching and uncoiling of the individual chains, which involves rotations around the covalent bonds with an adjustment of the bond angles. ${ }^{23}$ Similarly, polymers adjust to compressive stresses through rearrangements of the chains in order to achieve a close packing in the bulk. Such conformational changes of the polymer backbone can provoke a change of the electronic properties, notably in conjugated polymers, and this can be exploited to achieve a macroscopic mechanochromic response. Thus, conjugated polymers interact with light in accordance to their effective conjugation length, i.e., the structurally integer and fully conjugated segments of the polymer chain across which electron delocalization takes place. $^{24-26}$ As the effective conjugation length and the lowest energy optical transition of conjugated polymer chains are related, stressinduced changes of the conformation of the polymer backbone such as a transition from a planar to a non-planar conformation usually change the conjugation along a given segment 
and this structural perturbation leads to a shift of the corresponding absorption or emission band.

A prominent family of polymers that exhibit mechanochromism on the basis of this effect are poly(diacetylene)s. ${ }^{27-29}$ Wegner pioneered the UV-induced polymerization of suitably preorganized 1,4-diacetylenes that yields polymers with a backbone of alternating double and triple bonds (Figure 1). ${ }^{30,31}$ The conjugation along this conformationally hindered backbone is very sensitive to perturbations. Indeed, poly(diacetylene)s were found to display distinct color changes from blue to red (sometimes yellow) upon application of a stimulus. $^{28,32-34}$ The chromism of poly(diacetylene)s has been extensively investigated and is associated with conformational rearrangements of the polymer backbone, ${ }^{35-38}$ although these effects are apparently superimposed with a contribution from changes in the intermolecular interactions. ${ }^{32,39,40}$

The characteristic red-to-blue chromism of poly(diacetylene)s can be induced by a variety of stimuli, including mechanical force. Müller and Eckhardt reported that the visual color of poly(diacetylene) single crystal specimen changed from golden to green after exposure to compressive stresses. ${ }^{41}$ Polymerized monolayers of poly(diacetylene)s were also exposed to compressive stresses at the air-water interface. ${ }^{42}$ The strain of the applied surface pressure was sufficient to cause a reversible transition from a blue color at lower pressures to a red colored film at higher surface pressures. Similarly, shear forces were applied to multilayered poly(diacetylene) films on solid substrates by means of an AFM tip. ${ }^{43,44}$ This approach permitted creating locally strained regions with dimensions as small as $30 \mathrm{~nm}$, as evidenced by the characteristic red emission of perturbed poly(diacetylene)s among a nonfluorescent blue domain.
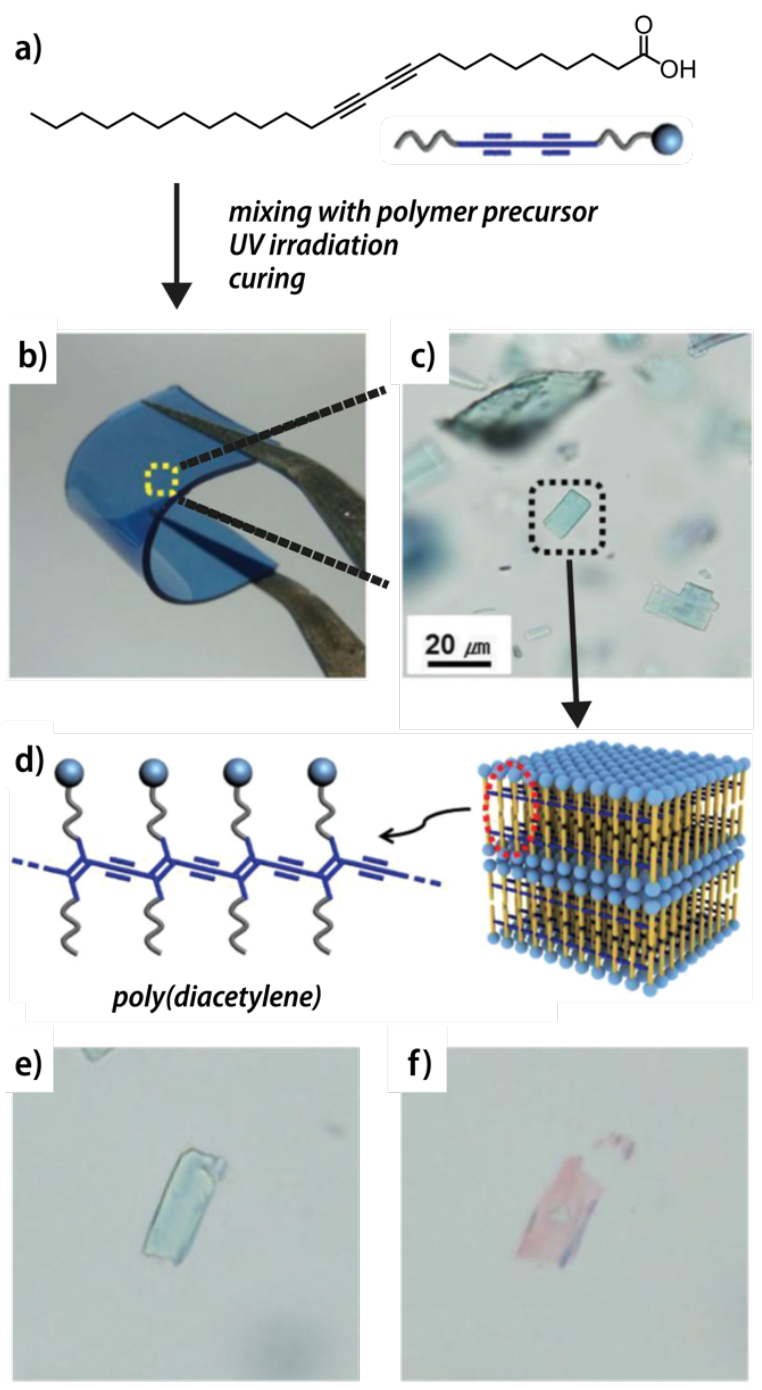

FIGURE 1 Mechanochromic poly(diacetylene)s can be embedded in poly(dimethylsiloxane) as elastomeric matrix and a chromic response is observed upon deformation. (a) Chemical structure of the diacetylene derivative 10,12pentacosadiynoic acid. (b) Photographic and (c) microscopic image of a polymer film with embedded poly(diacetylene) crystallites. (d) Schematic depiction of the poly(diacetylene) structure in the crystallites. (e) Optical microscopy image of a crystallite before and $(f)$ after swelling of the polymer film with octane. (Reproduced and adapted from [49], with permission from John Wiley \& Sons.) 
In addition to investigations involving the neat poly(diacetylene)s, poly(diacetylene) segments were also incorporated into different polymer matrices as force-sensitive probes. For example, Nallicheri and Rubner reported the preparation of poly(urethane)s that featured polymerizable diacetylenes in the hard segments. ${ }^{45-47}$ After processing the poly(urethane)s, the diacetylene polymerization was performed in situ. The resulting poly(diacetylene) domains were shown to serve as mechanochromic probes that can signal mechanical stress to the hard domains through a color change. The uniaxial deformation of the elastomers thus prepared caused clearly visible mechanochromism, with color changes from blue to red to yellow. For samples with crystalline hard domains, the mechanically induced color changes were found to be reversible below a strain level of $250 \%$; above this threshold, the deformation of the hard domains as well as the color changes became irreversible. Poly(diacetylene)s were also embedded in poly(ethylene oxide) wires and exposed to oscillatory forces that induced a chromic response. $^{48}$ Moreover, a poly(dimethylsiloxane) elastomer was used as a matrix and the strain of deformation upon hydrocarbon-induced swelling led to conformational changes of embedded poly(diacetylene)s that gave rise to a chromic response (Figure 1). ${ }^{49}$ The intensity of the response was found to be directly proportional to the swelling rate and thereby allowed for a visual differentiation of different linear alkanes.

Other polymers with $\pi$-conjugated backbones have been reported to display mechanicallyinduced chromic responses, as well. For example, the effect of compressive stress on films of poly(3-dodecylthiophene)s has been investigated by Yoshino and coworkers. ${ }^{50,51}$ The corresponding absorption and emission spectra displayed a reversible red shift at high pressures and the results were tentatively explained by a reduced torsion of the polymer backbone that led to an increased conjugation. These findings were later confirmed for different other poly(3alkylthiophene) derivatives. ${ }^{52-55}$ Detailed investigations of the mechanochromic response indicated that the spectral shifts were the result of the combined effects of a planarization of the backbone and intermolecular interactions at increased packing densities. Compressive stresses were shown to have similar effects on poly(acetylene)s, ${ }^{56,57}$ poly(phenylene) $s,{ }^{58}$ poly ( $p$ phenylene vinylene)s, ${ }^{59}$ poly(pyrrole) $s,{ }^{60}$ as well as poly(anthraquinone)s. ${ }^{55,61}$ In addition to such studies involving neat $\pi$-conjugated polymers, Shiga and coworkers dispersed poly(thiophene)s in a matrix of poly(methyl methacrylate) and observed a relation between the applied tensile load and the fluorescence behavior of the samples. ${ }^{62-64}$ Elastic deformation influenced the fluorescence decay times, while plastic deformation was accompanied by a reduced intensity and red-shift of the fluorescence signal.

The preceding examples highlight how the conformation of the conjugated backbone of polymers can be, typically reversibly, altered by application of mechanical stresses. As a result, the conjugation is either disrupted or a transition to conformations with an increased conjugation was observed. In both cases, the rearrangement can trigger a significant change of the absorption and emission properties of these materials. In addition to the conformational changes, intermolecular aggregation was often observed as a superimposed effect when investigating these polymers. In the following section we will discuss mechanochromic materials whose 
response predominantly originates from the formation or dispersion of such aggregates.

\section{AGGREGATION-BASED RESPONSES}

The absorption and emission properties of chromophores with conjugated $\pi$-electron systems are usually highly sensitive to the intermolecular distance and the geometric orientation within aggregates of the respective molecules. ${ }^{65-68}$ Accordingly, changing the molecular packing of such chromophores through mechanical forces can provide a direct pathway toward responsive mechanochromic materials.

While the aggregation of organic molecules or polymers typically causes strong fluorescence quenching, ${ }^{6,69}$ Ben Zhong Tang and coworkers pioneered the development of chromophores that display an increased emission in the aggregated state. $^{70}$ In early studies, the propeller-shaped, non-planar 1-methyl1,2,3,4,5-pentaphenylsilole was explored, which does not luminesce in dilute solutions due to rapid intramolecular rotations that facilitate the thermal relaxation of excited states. By contrast, the aggregation of these molecules leads to a coplanarization with restricted intramolecular rotations and an increased electron delocalization across the conjugated $\pi$ system. As a result, an intense fluorescence emission can be observed.

After these initial findings, materials that display such an aggregation-induced emission (AIE) have received considerable attention due to potential applications in photovoltaic cells, organic light-emitting diodes, or responsive sensing materials. ${ }^{71,72}$ Thus, series of AIE chromophores were developed, ${ }^{6,16}$ some of which display luminescent properties that change in response to mechanical grinding of the solids. ${ }^{14,73,74}$ In a recent example by Tang and coworkers, the preparation of a fluorescent 1,3-indandione substituted tetraphenylethene was reported (Figure 2). This chromophore displays AIE activity in combination with a visible mechanochromic response. ${ }^{75}$ In the solid-state, grinding of the yellow powder produced an orange solid and the fluorescence spectra showed a shift of the yellowish-green emission at $510 \mathrm{~nm}$ to a red-orange emission at $562 \mathrm{~nm}$ when excited at $365 \mathrm{~nm}$. Investigations by X-ray diffraction confirmed that the chromism was associated with mechanically a)

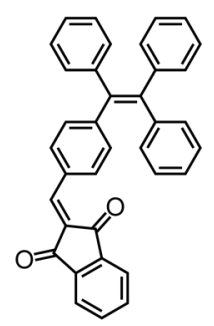

1,3-indandione-modified tetraphenylethylene b)

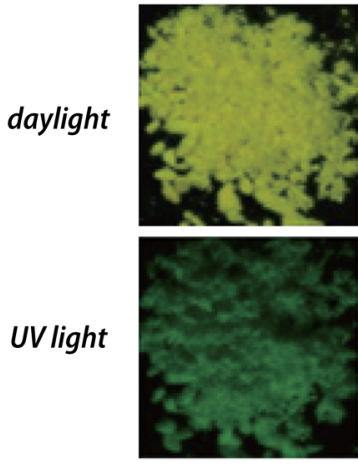

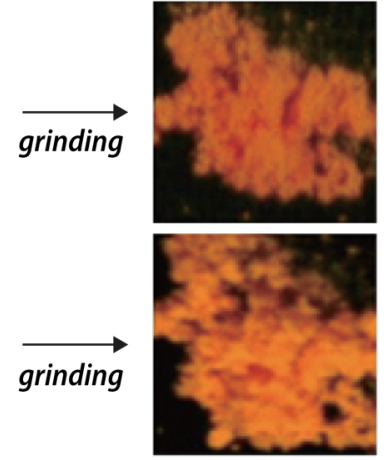
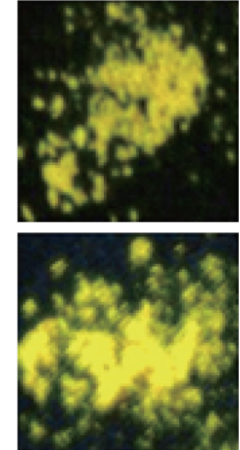

FIGURE 2 (a) Chromophores such as the 1,3-indandione-modified tetraphenylethylene show aggregation-induced emission. (b) Reversible mechanochromic transitions between the amorphous and crystalline state are observed for these compounds, as can be seen in photographs taken under ambient light (upper row) and under UV light (lower row, $\lambda_{\mathrm{ex}}=365 \mathrm{~nm}$ ) before and after grinding of the solids. (Reproduced and adapted from [75], with permission from John Wiley \& Sons.)

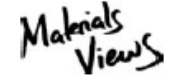

WWW.MATERIALSVIEWS.COM 
induced rearrangements of the molecules and a transition from the crystalline to the amorphous state. While these examples are promising, the complex interplay of the interactions between chromophores and a polymer matrix have so far stifled the widespread implementation of such chromophores in mechanoresponsive polymeric materials that exploit the AIE effect. ${ }^{6}$ An example reported by Rowan and coworkers might be considered as a notable exception. ${ }^{76}$ The authors employed square-planar complexes of platinum with 4-dodecyloxy-2,6-bis $(N$ methylbenzimidazol-20'-yl)pyridine and dispersed these in different acrylic polymers such as poly(methyl methacrylate) or poly(butyl methacrylate). Films of these polymers displayed a pronounced red-shifted emission of increased intensity upon application of compressive stresses, which was explained by structural rearrangements that led to the formation of short-range, intermolecular Pt-Pt interactions. Apparently, only a minor fraction of the intermolecular aggregates with short contacts were formed, but their highly emissive nature dominated the spectra. Moreover, Sottos, Moore and coworkers recently demonstrated the potential benefits of the AIE effect by employing core-shell microcapsules filled with dilute solutions of 1,1,2,2-tetraphenylethylene. $^{77}$ The mechanical disruption of capsules embedded in polymer matrices reliably led to an aggregation of the released chromophores and a strong, turn-on fluorescence signal facilitated the visual detection of microscopic damages to the material.

Aggregation dependent changes of the emission properties of excimer forming chromophores were employed by Weder and coworkers who pioneered the use of excimer-forming dyes and their dispersion in suitable polymer matrices for the preparation of mechanochromic fluorescent materials. Thus, cyano-substituted oligo( $p$ phenylene vinylene) derivatives (cyano-OPV) were employed as luminescent chromophores that show a pronounced bathochromic shift, for example derivatives with methoxy substituents on the central phenyl ring displayed a shift from a red emission centered at $644 \mathrm{~nm}$ in the crystalline state to a green emission at $538 \mathrm{~nm}$ in dilute solution. ${ }^{78,79}$ The chromophores were first dispersed in linear low-density poly(ethylene) through a swelling-induced diffusion process. The fluorescence of these polymer films exhibited a pronounced red excimer emission that was associated to aggregates of the dye molecules in the polymer matrix. Tensile deformation of the films disrupted the aggregated chromophores and resulted in a chromic response as the fluorescence shifted to the green, monomerdominated emission. These initial findings were subsequently expanded and the conditions of the blending procedure were optimized to allow for direct melt processing (Figure $3 a, b) .{ }^{80}$ Fast quenching of the blends and plasticization of the polymer matrix was key to prevent largescale phase segregation when higher dye concentrations were employed, as blends that featured microscopic aggregates on the order of $10 \mu \mathrm{m}$ did not show mechanochromism. Moreover, cyano-OPV derivatives with longer alkyl chains were synthesized in order to decrease their solubility in polar matrices and furnish higher nucleation rates that promote the formation of small aggregates. This modification allowed for the preparation of excimer-containing blends with other polymer matrices such as poly(ethylene terephthalate) and poly(ethylene terephthalate glycol). ${ }^{81,82}$ Gratifyingly, all these blends showed a change of the fluorescence color upon application of mechanical stresses as the chromophore aggregates were disrupted. Selected cyano-OPV 
a)

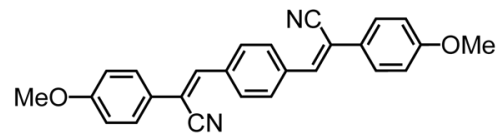

1,4-bis(a-cyano-4-methoxystyryl)benzene

b)

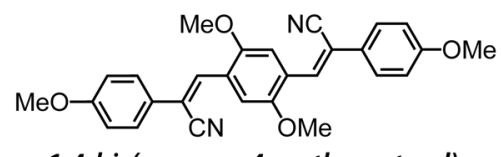

1,4-bis(a-cyano-4-methoxystyryl)2,5-dimethoxybenzene

c)

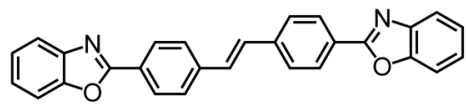

4,4'-bis(2-benzoxazolyl)stilbene
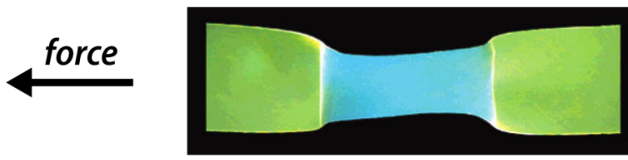

force
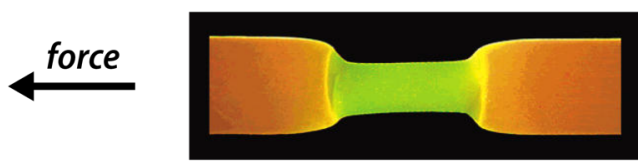

force
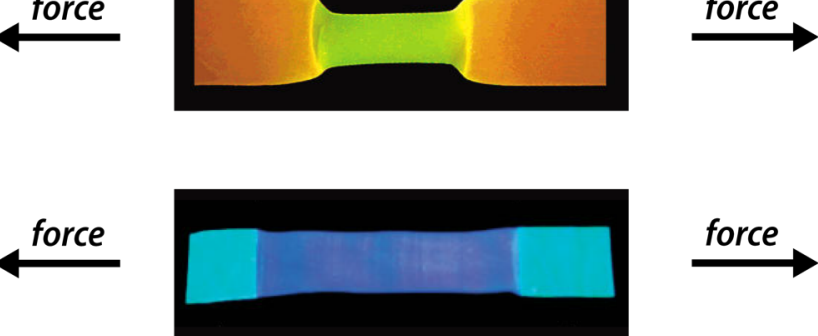

FIGURE 3 Selected aggregachromic dyes and images of the corresponding polymer films after tensile deformation recorded under UV light. (a) 1,4-Bis( $\alpha$-cyano-4-methoxystyryl)benzene and (b) 1,4-bis( $\alpha$ cyano-4-methoxystyryl)-2,5-dimethoxybenzene in linear low-density poly(ethylene). (c) 4,4'-Bis(2-benzoxazolyl)stilbene in poly(propylene). (Reproduced from [80, 83], with permission from American Chemical Society, John Wiley \& Sons.)

derivatives also displayed a significant bathochromic shift of the absorption bands upon aggregation. ${ }^{81}$ However, mechanochromic materials that displayed a macroscopically discernible change of the absorption were only obtained when mechanical stresses led to a very efficient disruption of the aggregated chromophores, (almost) exclusively leaving well dispersed monomeric species in the strained regions of the polymer films. Thus, a pronounced change of the optical properties needs to arise in a large fraction of the chromophores to obtain materials with desirable properties.

Following a similar approach, Pucci and coworkers explored the use of stilbene derivatives to create polymers with mechanoresponsive luminescent behavior. ${ }^{83}$ Commercially available 4,4'-bis(2-benzoxazolyl)stilbene featured an excellent dispersibility in addition to a high melting point $\left(360^{\circ} \mathrm{C}\right)$ and degradation temperature $\left(380^{\circ} \mathrm{C}\right)$, making it an ideal candidate as additive for thermoplastics.
Thus, different concentrations of the chromophore were well dispersed in the amorphous phase of poly(propylene) films through a melt-mixing process at $260^{\circ} \mathrm{C}$. Above a dye concentration of $0.2 \mathrm{wt} \%$, the absorption of the blends was found to be concentration independent and a new emission band at $500 \mathrm{~nm}$ emerged in the fluorescence spectra. This suggested the successful formation of excimer-type aggregates. When these polymer films were exposed to tensile deformation, the green emission color changed to the blue color of the monomer (Figure 3c). In addition to a disruption of the aggregates, measurements with polarized light indicated that the chromophores adopted a uniaxial alignment along the stretching direction. These chromophores were subsequently also employed with other thermoplastics such as aliphatic polyesters and poly(1,4-butylene succinate). ${ }^{84}$ Pucci and coworkers also explored the use of aggregates of perylene derivatives for the preparation of mechanochromic materials. ${ }^{85,86}$ Similarly to the previous 
examples, linear low-density poly(ethylene) was melt-processed with different amounts of perylene and the prepared films exhibited a pale yellow color with well-defined absorption and emission bands characteristic for the formation of dye aggregates. Tensile deformation disrupted the aggregates and the films showed the blue luminescence of individual perylene molecules.

Similar principles are at play in mechanochromic materials based on macromolecules that carry the corresponding chromophores in the polymer backbone or as pendant groups. ${ }^{87}$ ${ }^{89}$ In all cases, the mechanical stress imparted by tensile deformation could be transferred to aggregates of the polymer-linked chromophores. The disruption of these aggregates was then observed through changes of the absorption and emission properties. Sufficient forces to disrupt the aggregates were typically achieved in the regime of plastic deformation of the polymer matrices. While tailored blends with such chromophore-containing polymers can be readily prepared, aggregate formation and stress-transfer to the aggregates can be challenging, especially in polymers with high segmental mobility such as thermoplastic poly(urethane)s. The dispersion of chromophores in a polymer melt is, by comparison, synthetically less complex and lower dye concentrations are sufficient to achieve successful aggregate formation.

Dispersions of two different chromophores might also be used to probe mechanical stresses in polymeric specimen. Thus, the efficiency of the fluorescence resonance energy transfer (FRET) process between donor and acceptor molecules is highly dependent on the intermolecular distances. ${ }^{90,91}$ Sijbesma and Karthikeyan explored the use of naphthalimide (acceptor) and 4-methylcoumarin (donor) derivatives as a FRET pair to detect mechanical stresses in thermoplastic elastomers with alternating blocks of soft poly(tetramethylene oxide)s and hard bisureas. ${ }^{92}$ The donor molecules were anchored to the hard blocks of the polymers through hydrogen bonding, while the acceptor molecules were either randomly dispersed or placed at the center of a telechelic polymer carrying two donor molecules at the termini. The latter systems displayed superior stress-sensing properties as tensile elongation of the samples by $100 \%$ led to a decrease of the FRET intensity ratio by $35 \%$. For comparison, polymers with randomly dispersed acceptors only showed similar responses after elongation by more than $300 \%$. The alteration of the donor-acceptor distance of a FRET pair was also used to detect compressive stresses. Thus, Lee and Jee dispersed rhodamine 123 (donor) and azulene (acceptor) in an ethylene/1-octene copolymer, exposed the films to compressive stresses in nanoindentation experiments with an AFM, and monitored the fluorescence decay times of the donor chromophores as a measure of the efficiency of the FRET process. ${ }^{93}$ The energy transfer efficiency was enhanced by a factor of two as the donor-acceptor distances were reduced with increasing indentation depth.

In summary, the formation or disruption of intermolecular aggregates has emerged as an efficient approach for the preparation of mechanochromic materials. However, most of the reported examples involve fluorescent polymers, which rely on the often very large difference of the emission properties of aggregated and isolated chromophores or energy transfer pairs. The exploitation of similar principles for the creation of materials that display similarly pronounced non-fluorescent 
mechanochromic responses, e.g., large changes in the absorption properties, appears more difficult. Unless charge-transfer effects are at play, the changes of the absorption spectrum resulting from the (de)aggregation of chromophores are usually small and therefore a large fraction of these molecules must be "switched" to elicit an appreciable optical change. It appears that the development and investigation of such materials deserves further attention, as the mentioned obstacles are not of fundamental nature and because for many applications color changing (as opposed to fluorescence color changing) mechanochromic materials seem preferable.

\section{MECHANICALLY INDUCED CLEAVAGE OF COVALENT AND NON-COVALENT BONDS}

The development of polymeric materials that respond to mechanical stresses through the ideally selective cleavage of predefined weak links - so called mechanophores - is another approach toward chromic materials that has recently seen significant progress. ${ }^{18,19,21}$ In such materials, macroscopic mechanical stresses are directly translated into responses on the molecular level, where chemical reactions alter the chemical structure of the mechanophore. Such mechanically triggered reactions may be exploited to create a broad range of functions, which depend on the specific design of the mechanophore, and can include a change of the absorption or emission properties, rendering these materials mechanochromic. To enable stress transfer to the force-responsive moieties, they must be integrated with a polymer matrix and examples of suitable covalent as well as non-covalent mechanophores that display a chromic response have been reported.

\section{Chromic Responses of Polymers with Covalent Mechanophores}

The first reports of mechanochemistry date back to Staudinger and the observation that high shear forces can induce a decrease of the molecular weight of poly(styrene) on account of the mechanically induced scission of covalent bonds. ${ }^{94}$ The deliberate force-induced cleavage of polymers at specific active sites is a much more recent development. ${ }^{18,19,21}$ Several mechanophores that undergo a well-defined chemical reaction upon application of a sufficiently high mechanical force have been explored in this context. The bond scission can occur homo- or heterolytically, but pericyclic reactions have been reported, as well. Whereas mechanochemical transformations of polymers in dilute solutions have become routine, ${ }^{95}$ similar mechanochemical transductions of polymers that support useful functions in solid materials have been more difficult to achieve. ${ }^{96}$ In the case of chromic mechanophores, this would provide the ultimate means of detecting and understanding the effects of deformation in polymeric materials.

Moore, Sottos, White and coworkers were the first to report synthetic polymers that displayed mechanochromic behavior induced by deliberate mechanical activation of chemical reactions. ${ }^{97}$ In their pioneering study, a spiropyran moiety was covalently embedded into the backbone of poly(methyl acrylate) or employed as cross-linker in poly(methyl methacrylate). Tensile deformation or compressive stresses permit a (reversible) electrocyclic ring-opening reaction of the colorless spiropyran to afford the highly colored merocyanine (Figure 4a). The spiropyran, hence, acted as a molecular force sensor that was embedded in the investigated polymers. The distinct color changes provided the possibility for a visible detection and

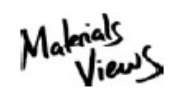

WWW.MATERIALSVIEWS.COM 
mapping of mechanical stresses within the bulk polymeric materials. Indeed, the most intense coloration was localized in regions of the highest deformation.

Several spiropyran derivatives have been thereafter utilized to prepare a broad range of polymer systems that display a chromic response to mechanical stimuli. ${ }^{98}$ Recent examples include their incorporation in the center of the poly(n-butyl acrylate) block of triblock copolymers of poly(styrene)- $b$-poly $(n$ butyl acrylate)- $b$-poly(styrene). ${ }^{99}$ In the latter materials, the poly(styrene) blocks form a hard phase, and their fraction determined the stress at which a mechanochromic response was observed. This example nicely demonstrates that the choice of the general design permits tailoring the properties of the mechanochromic materials. Spiropyran derivatives have also been embedded in the backbone of supramolecular polymers based on metal-ligand interactions or hydrogen bonding to create polymers that combine good mechanical performance, self-healing properties, and stress sensing capabilities. ${ }^{100-103}$ For example, spiropyrans were incorporated in the backbone of telechelic, ureidopyrimidinone-terminated polymers and tensile deformation led to an efficient stress transfer to the mechanochromic spiropyrans. ${ }^{102}$ Moreover, the use of the spiropyran-motif in soft robotics has also been reported. Thus, the mechanophore was cured into a molded poly(dimethylsiloxane) soft robot walker and gripper. ${ }^{104}$ The color change was then employed to detect high mechanical stresses and places where failure was most probable to occur displayed the most intense a)<smiles>COc1ccc2c(c1)C(C)(C)[C@@]1(CCc3cc([N+](=O)[O-])cc(OC)c3C1)N2C</smiles>

b)

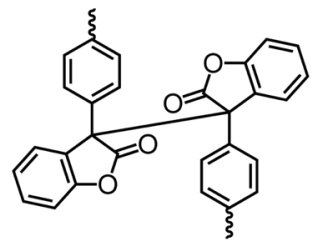

c)

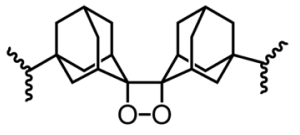

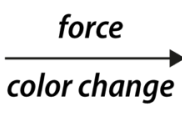
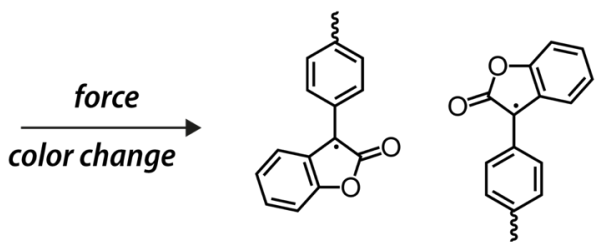

dark

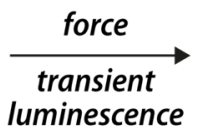<smiles>COc1cc(/C=C/C2(C)c3cc(OC)ccc3[N+]2C)cc([N+](=O)[O-])c1</smiles>
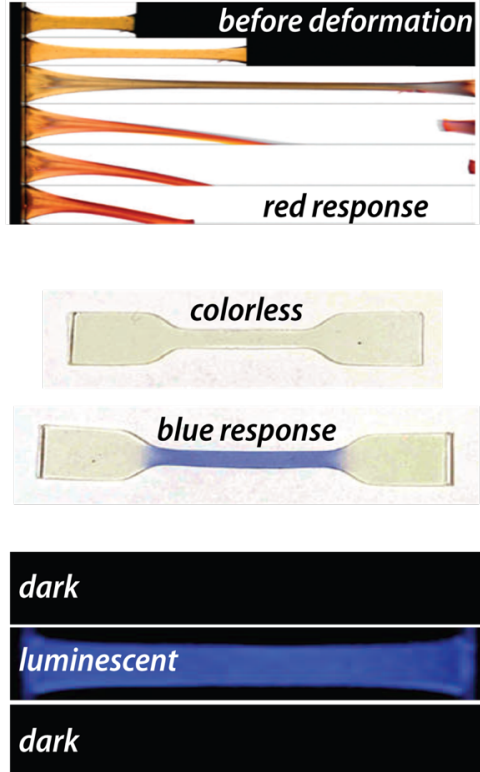

FIGURE 4 Selected mechanophores that display a chromic response after mechanical activation. (a) The spiropyran moiety can be embedded in polymer chains such as poly(methyl methacrylate) and mechanical activation leads to the formation of the colored merocyanine. (b) Diarylbibenzofuranone mechanophores were embedded in poly(urethane)s and display a chromic response upon tensile deformation. (c) Bis(adamantyl) 1,2-dioxetane was embedded in poly(methyl acrylate) and mechanical activation causes a pericyclic reaction of the strained four-membered ring with concomitant brightblue luminescence. (Reproduced and adapted from [8, 97, 112], with permission from [American Association for the Advancement of Science, Nature Publishing Group, Royal Society of Chemistry].) 
coloration. In an effort to prepare materials that display load-triggered cross-linking in addition to a chromic response, Weng and coworkers embedded spirothiopyran derivatives in the backbone of poly(urethane)s and poly(ester)s. ${ }^{105}$ Isomerization of the spirothiopyran mechanophores under mechanical stress yielded the corresponding thiomerocyanines, whose thiolate moieties underwent addition reactions with suitable alkenes. Thus, reaction with 1,6-bismaleimidohexane in solution led to a cross-linking of the polymer chains. While a similar reactivity has yet to be demonstrated in the solid state, corresponding materials promise to signal as well as reinforce sample regions that experience mechanical stresses.

Following a similar approach, a rhodamine derivative has been recently embedded in the backbone of poly(urethane)s and the polymer films prepared from these materials exhibited a reversible mechanochromic response to stresses applied through shearing or compression. ${ }^{106}$ This response is related to a ring-opening isomerization of the rhodamine from a twisted spirolactam to a planar zwitterionic amide derivative. In an effort to further improve the optical stress-sensing of mechanophores, Sijbesma and coworkers recently reported a 9- $\pi$-extended anthracene. ${ }^{107}$ When the maleimide Diels-Alder adducts were embedded as mechanophores in poly(hexyl methacrylate), they could be mechanically activated in the solid state through compression. Solution-phase experiments served to demonstrate that the 9$\pi$-extended anthracenes that were obtained after the stress-induced cycloreversion reaction featured a fluorescence quantum yield $\Phi_{f}$ of 0.72 that was almost two orders of magnitude higher than the values of spiropyran mechanophores. Moreover, embedding basesensitive chromophores into amine-containing epoxides allowed for the preparation of mechanochromic materials that were highly sensitive to compressive stresses. ${ }^{108}$ An elimination reaction was triggered by the coordination of the amines to the chromophore, which led to an increased conjugation in the latter and a visible change in the absorption as well as emission spectra of the material. Low compressive strains $(\varepsilon=0.14)$ were sufficient to trigger a visually detectable response, rendering this system highly useful for the detection of impact damages.

The formation and propagation of cracks is a dominant failure mode upon application of mechanical stresses and Chung and coworkers employed films of fluorescent mechanoresponsive polymers to facilitate the detection and analysis of cracks. ${ }^{109,110}$ Thus, monomers equipped with three cinnamoyl groups were drop-cast onto the surface of polymeric substrates. Subsequent irradiation led to a polymerization through [2+2]photocycloaddition reactions between the cinnamoyl moieties, furnishing cyclobutane-containing polymer films on the surface of the substrates. $^{109}$ The application of mechanical stresses by grinding or crack formation led to cycloreversion reactions that yielded the strongly fluorescent cinnamoyl motifs. Similarly, dimeric anthracene derivatives were employed to cross-link poly(vinyl alcohol). The cross-linked polymers were then used to coat plastic substrates. ${ }^{110}$ Crack formation through bending of the substrates gave rise to a strong fluorescence signal with maxima in the range of 500-600 nm.

Another option to visualize and quantify covalent bond scission is the stress-induced 
formation of stable, colored radicals. For example, Otsuka and coworkers reported a diarylbibenzofuranone mechanophore that could be embedded in the backbone of poly(urethane)s when its diol derivative was copolymerized with poly(ethylene glycol) and hexamethyldiisocyanate. ${ }^{111}$ Alternatively, crosslinked poly(urethane)s were obtained when a similar tetraol derivative was employed in the same polyaddition reaction. The cleavage of the mechanophore in cross-linked gels was achieved upon freezing of the sample, resulting in blue colored stable radicals that recombined after thawing. The activation of the mechanophores was found to be solventdependent. Presumably, the coagulation of the solvent upon freezing exerts mechanical force on the polymer network. Intriguingly, however, mechanical strain applied through tensile, compressive, or shear forces as well as fracture or swelling did not lead to a chromic response. The authors suggest that fast relaxation and recombination processes of formed radicals impede their detection. By contrast, when the same mechanophore was incorporated in poly(urethane)-based thermoplastic elastomers, a reversible formation of blue radicals upon tensile deformation was observed (Figure $4 b$ ). ${ }^{112}$ Performing tensile deformation in multiple cycles showed a repeated coloration and fading of the mechanophores and the amount of stress in the samples could be quantified by means of in situ electron paramagnetic resonance measurements. ${ }^{113}$

Structural motifs that respond to mechanical stimulation through the emission of light were pioneered by Sijbesma and coworkers, ${ }^{114}$ who incorporated a bis(adamantyl) 1,2-dioxetane in the center of poly(methyl acrylate). Mechanical activation in solution by means of sonication caused a pericyclic reaction of the strained four- membered ring, concomitant with bright-blue luminescence. Addition of suitable acceptor chromophores led to energy transfer and allowed for a tuning of the emission color. The scission of this mechanophore could also be achieved in the solid state and mechanoluminescent responses in thermoplastic elastomers could be demonstrated. ${ }^{115}$ The mechanofluorescence of 1,2-dioxetanes provided an effective means to monitor the chain-scission events that occurred upon tensile deformation of these polymers in real time. The ability of these motifs to serve as stress-sensors was also exploited in a recent study in which the mechanical reinforcement of elastomers was investigated. ${ }^{8}$ The toughening of the elastomers was achieved by preparing triple interpenetrating networks. The first network featured shorted chains of poly(ethyl acrylate), while the second and third network consisted of longer poly(methyl acrylate) segments. The first network provided resistance to initial deformation and preferentially broke, resulting in energy dissipation and preventing crack propagation. These details of the failure mechanism of the materials were confirmed by incorporating dioxetanes into the first network (Figure 4c). The mechanochromism of the dioxetanes facilitated the analysis of the failure modes upon tensile deformation by visualizing the bond-breakage in the vicinity of the propagating crack. Recently, Sijbesma and coworkers reported the use of mechanoluminescent dioxetanes to investigate the processes of stress-softening and mechanomemory in filled elastomers. ${ }^{116}$ These reports showcase how suitable mechanochromic moieties can serve as analytical tools for the investigation of the failure of soft materials and aid in the development of better models, which might 
ultimately lead to the preparation of novel materials with improved properties.

\section{Chromic Responses of Polymers with Non- Covalent Mechanophores}

Many of the examples of mechanochromic materials that respond with the scission of covalent bonds require relatively high forces to trigger a response. By contrast, mechanotransduction in biological systems is often activated by small forces, which is at least in part related to the fact that many natural materials are soft and in most cases contain significant amounts of water. ${ }^{117-119}$ Examples that are found in nature are based on conformational rearrangements in proteins or changes in supramolecular architecture. Researchers are increasingly taking inspiration from the design principles found in nature and have sought to exploit the dissociation of noncovalent interactions for the preparation of mechanochromic materials. ${ }^{22}$

Early nanoscale force sensors were prepared by Bruns et al. who combined donor and acceptor type proteins that display fluorescence resonance energy transfer with so-called thermosome proteins that unfold along their mechanically weakest section upon mechanical stimulation. $^{120}$ The protein complex was embedded in poly(acrylamide)s and mechanical deformation led to a loss in the intensity of the fluorescence signal as the donor and acceptor proteins were separated. More recently, Bruns and coworkers reported the preparation of fiber-reinforced composites that utilized biomolecules to signal damages at the

a)

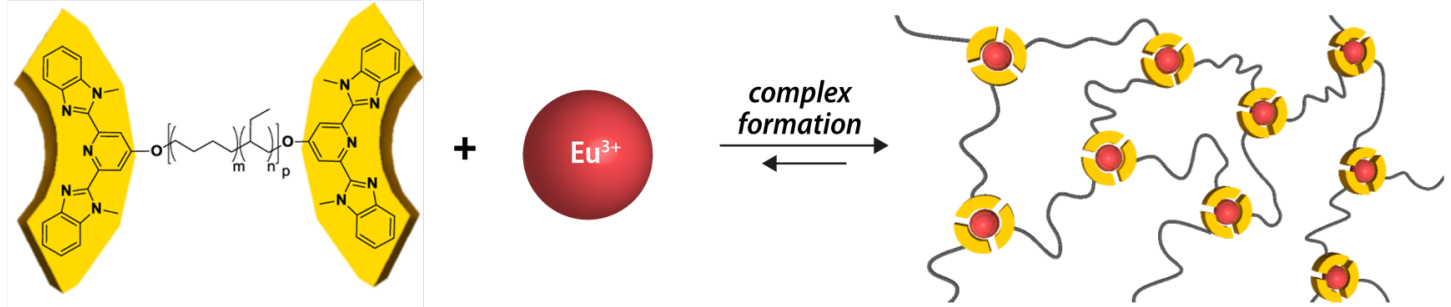

b)

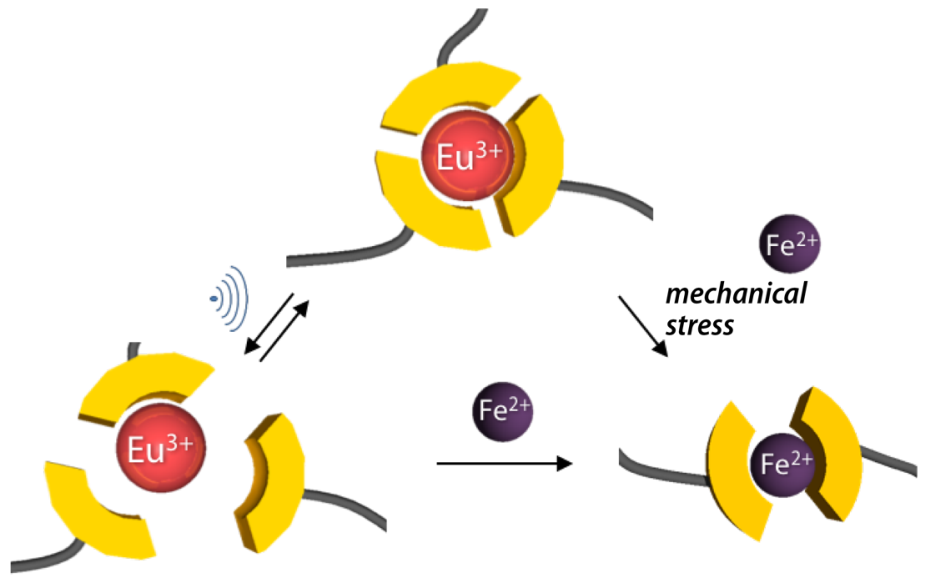

c)

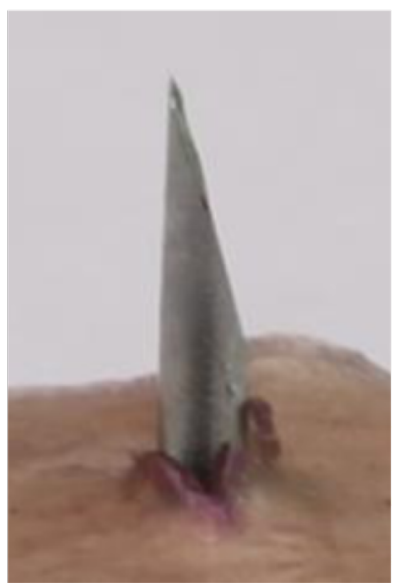

FIGURE 5 Non-covalent mechanochromic materials based on metallosupramolecular polymers. (a) Chemical structure of the telechelic polymers and schematic representation of their self-assembly into a network by complex formation with $\mathrm{Eu}^{3+}$ ions. (b) Reversible dissociation of the complexes upon sonication as well as irreversible metal exchange with $\mathrm{Fe}^{2+}$ ions. (c) Films imbedded with $\mathrm{Fe}\left(\mathrm{ClO}_{4}\right)_{2}$ change their color after puncturing with a needle. (Reproduced from [125], with permission from American Chemical Society.) 
micrometer scale. ${ }^{121}$ This was achieved by placing an enhanced yellow fluorescent protein at the interface between glass fibers and an epoxy resin matrix. The materials signaled fiber fracture as well as debonding between fibers and matrix as the forces at the interface led to an unfolding of the embedded proteins that was accompanied by a loss of its yellow fluorescence. Schaaf, Schiller, and coworkers covalently grafted genetically modified green fluorescent proteins onto a poly(dimethyl siloxane) surface and showed that uniaxial mechanical stresses resulted in a fully reversible linear decrease of the fluorescence intensity that was attributed to conformational changes of the protein. ${ }^{122}$ Moreover, fluorescent proteins were also employed in polymer matrices and their fluorescence signal was used to facilitate the detection of compressive stresses. ${ }^{123}$ These mechanochromic materials rely on the unfolding of complex proteins to induce a color change and demonstrate how a chromic response can be achieved on the basis of non-covalent interactions.

Also relying on the mechanically induced disassembly of supramolecular interactions, non-covalent mechanochromic materials were developed that employ metallosupramolecular polymers with metal-ligand complexes as the mechanophores. Inspired by shake-responsive behavior of metallosupramolecular polymers reported by Rowan et al., ${ }^{124}$ Weder and coworkers relied on the complex formation between europium salts and telechelic poly(ethylene-co-butylene) with 2,6-bis(1'methylbenzimidazolyl)pyridine ligands at the termini to obtain a supramolecular network (Figure 5). ${ }^{125}$ The metal-ligand complexes served as mechanophores that displayed a simultaneous chromic response. Reversible and dose-dependent disassembly of the complexes was induced for solutions of these polymers through application of ultrasound pulses. The fluorescence signal of the complex thereby served as an internal optical probe that allowed for a direct monitoring of the state of (dis)assembly. Moreover, when iron salts were imbedded in films of this polymer, mechanical disruption with a needle led to disassembly of the europium complexes, as evidenced by the formation of the thermodynamically favored iron complexes and a visible color change.

In similar metal-ligand systems a terpyridyl-endcapped four arm poly(ethylene glycol) polymer was complexed with lanthanide ions. ${ }^{126} \mathrm{~A}$ wide range of stimuli-responsive behaviors of these metallosupramolecular polymer gels was observed, including a chromic response to

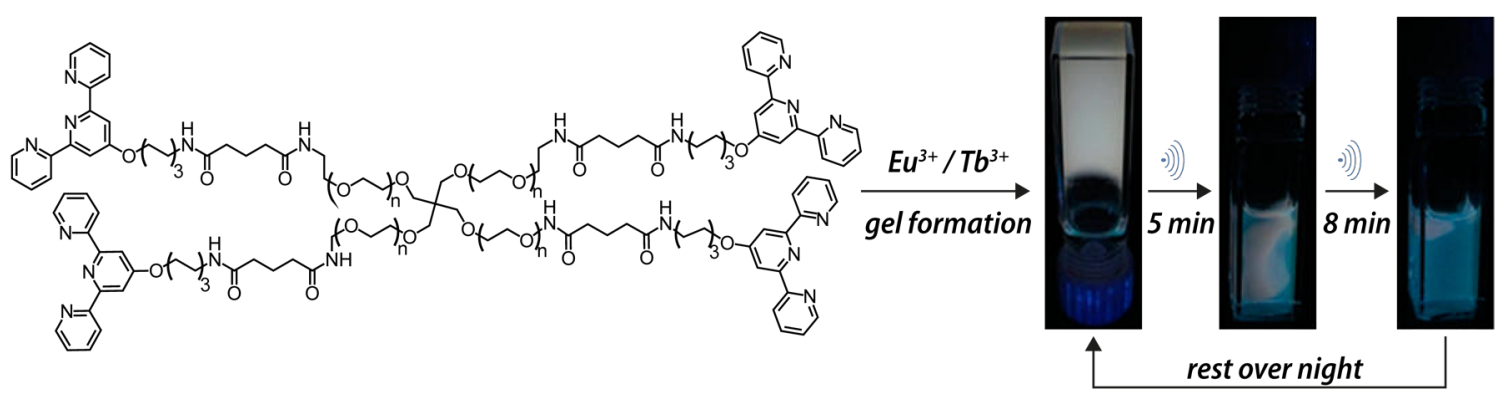

FIGURE 6 A mechanoresponsive, white luminescent metallosupramolecular polymer gel is obtained when a four-arm star polymer with terpyridyl ligands forms complexes with $\mathrm{Eu}^{3+}$ and $\mathrm{Tb}^{3+}$ ions. Sonication leads to a gel-sol phase transition and the initially white gel becomes a blue liquid. (Reproduced and adapted from [126], with permission from American Chemical Society.) 
mechanical stress (Figure 6). Thus, sonication of self-assembled white luminescent gels resulted in a breakdown of the supramolecular network and the blue fluorescence of the obtained fluid indicated the presence of unbound ligand. Spectroscopic investigations confirmed partial cleavage of the complex-based cross-links. Such supramolecular polymers are envisioned as a versatile platform for the development of mechanochromic polymeric materials that can benefit from the tunable interaction strength and the dynamic, reversible nature of the supramolecular interactions.

\section{CONCLUSIONS}

The development of mechanochromic materials has been inspired by the potential benefits of predicting mechanical failure as well as the desire to signal and detect the impact of mechanical stress and wear on polymeric objects. In this context, an advanced understanding of the processes that take place in polymeric specimen upon mechanical deformation has been both accompanied and perpetuated by the development of mechanochromic materials with improved properties. The approaches toward such materials have evolved from the use of conjugated polymers that undergo conformational changes of their backbone upon application of mechanical stimuli to the stress-induced dispersion of chromophore aggregates in polymer matrices. More recently, the controlled scission of covalent bonds or cleavage of non-covalent interactions have become mechanisms of choice for the preparation of polymer-based mechanochromic materials.

The conditions under which a material will be employed might be the most critical parameter that needs to be considered when choosing between different design approaches. Thus, many of the chromogenic moieties that respond to mechanical deformation can also be activated by other means. When the chromogenic units are, for example, responsive to light or temperature changes, practical issues and a complication of the analysis might ensue. Another important criterion is the envisioned mode of detection, which directly results from the type of response, i.e., whether changes in emission or absorption properties occur. Many of the reported materials rely on changes in the emission properties that are typically more straightforward to discern when bulk samples are investigated. Provided that the spectral changes are significant and a sufficient fraction of the chromophores in the system contribute, macroscopically detectable mechanochromic responses based on the absorption properties can also be achieved. However, the background color of embedded chromophores that have not been activated can impede the detection of a chromic response that is based on changes of the absorption. At the same time, it would be highly desirable to be able to detect the color changes without the necessity to excite the respective materials throughout the analysis. An intriguing opportunity in this regard that has only been scarcely investigated is the use of charge-transfer complexes. ${ }^{127}$ The typically large color changes between the complex and the individual donor and acceptor moieties renders them ideal candidates.

Whether a response is reversible or permanent is determined by the nature of the physical or chemical changes that provoke a chromic response in polymeric materials, both with respect to the chromogenic moieties and the deformation behavior of the matrix. Indeed, the mechanical properties and the deformation behavior of the surrounding matrix exert a large influence on the magnitude of the forces that

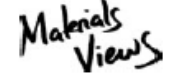

WWW.MATERIALSVIEWS.COM 
the chromogenic moieties may experience. This appears to make the realization of mechanochromic effects particularly challenging in rigid materials, specifically in glassy polymers, where the selective mechanical activation of an embedded chemical motif (as opposed to random events) may be difficult to achieve.

To conclude, the field of mechanochromic materials has seen significant progress and many opportunities remain. Especially the recent developments in mechanochemistry have led to a surge in the development of polymeric materials that respond to mechanical deformation in a useful manner.

\section{ACKNOWLEDGEMENTS}

The authors gratefully acknowledge financial support through the National Center of Competence in Research (NCCR) Bio-Inspired Materials, a research instrument of the Swiss National Science Foundation (SNF) as well as funding from the Adolphe Merkle Foundation. The research leading to these results has received funding from the European Research Council under the European Union's Seventh Framework Programme (FP7/2007-2013) / ERC grant agreement $n^{\circ}$ ERC-2011-AdG 291490MERESPO.

\section{REFERENCES AND NOTES}

1. P. Bamfield, In Chromic Phenomena; Royal Society of Chemistry: Cambridge, UK, 2001.

2. M. Ferrara, M. Bengisu, In Springer Briefs in Applied Sciences and Technology: Materials that Change Color; B. Pernici, S. Della Torre, B. M. Colosimo, T. Faravelli, R. Paolucci, S. Piardi, Eds.; Springer: Heidelberg, 2014 pp. 9-60.

3. A. Pucci, G. Ruggeri, J. Mater. Chem. 2011, $21,8282$.

4. D. R. T. Roberts, S. J. Holder, J. Mater. Chem. 2011, 21, 8256.

5. F. Ciardelli, G. Ruggeri, A. Pucci, Chem. Soc. Rev. 2013, 42, 857-870.
6. Z. Chi, J. Xu, In Aggregation-Induced Emission: Fundamentals and Applications; A. Qin, B. Z. Tang, Eds.; John Wiley and Sons Ltd: Chichester, United Kingdom, 2013 pp. 61-86.

7. C. Weder, In Encyclopedia of Polymeric Nanomaterials; Springer Berlin Heidelberg: Berlin, Heidelberg, 2014 pp. 1-11.

8. E. Ducrot, Y. Chen, M. Bulters, R. P. Sijbesma, C. Creton, Science 2014, 344, 186-189.

9. R. J. D. Tilley, In Colour and the Optical Properties of Materials; John Wiley \& Sons, Ltd: Chichester, UK, 2010.

10. J. Ge, Y. Yin, Angew. Chem. Int. Ed. 2011, 50, 1492-1522.

11. P. Vukusic, J. R. Sambles, Nature 2003, 424, 852-855.

12. P. Ball, Sci. Am. 2012, 306, 74-79.

13. Y. Sagara, T. Kato, Nature Chem. 2009, 1, 605-610.

14. Y. Hong, J. W. Y. Lam, B. Z. Tang, Chem. Soc. Rev. 2011, 40, 5361.

15. Z. Chi, X. Zhang, B. Xu, X. Zhou, C. Ma, Y. Zhang, S. Liu, J. Xu, Chem. Soc. Rev. 2012, 41, 3878-3896.

16. Y. Sagara, S. Yamane, M. Mitani, C. Weder, T. Kato, Adv. Mater. 2016, 28, 1073-1095.

17. R. D. Astumian, A. Balan, A. Barge, M. J. Buehler, B. Cheng, P. Cintas, J. M. Clough, G. Cravotto, S. Cui, A. P. Haehnel, G. S. Heverly-Coulson, G. Jung, G. S. Kochhar, Y. Li, Y. Lin, K. Martina, N. J. Mosey, Z. Qin, Y. Sagara, M. J. Serpe, S. S. Sheiko, R. P. Sijbesma, Y. C. Simon, C. Weder, W. Weng, Y. Xu, H. Zhang, Q. M. Zhang, In Polymer Mechanochemistry; R. Boulatov, Ed.: Springer: Heidelberg, 2015.

18. M. K. Beyer, H. Clausen-Schaumann, Chem. Rev. 2005, 105, 2921-2948.

19. M. M. Caruso, D. A. Davis, Q. Shen, S. A. Odom, N. R. Sottos, S. R. White, J. S. Moore, Chem. Rev. 2009, 109, 5755-5798.

20. A. L. Black, J. M. Lenhardt, S. L. Craig, J. Mater. Chem. 2011, 21, 1655-1663.

21. J. Li, C. Nagamani, J. S. Moore, Acc. Chem. Res. 2015, 48, 2181-2190.

22. P. Lavalle, F. Boulmedais, P. Schaaf, L. Jierry, Langmuir 2016, 32, 7265-7276. 
23. R. J. Young, P. A. Lovell, In Introduction to Polymers, Third Edition; CRC Press: Boca Raton, US, 2011.

24. D. N. Batchelder, Contemp. Phys. 1988, 29, 3-31.

25. H. Meier, U. Stalmach, H. Kolshorn, Acta Polymerica 1997, 48, 379-384.

26. R. E. Martin, F. Diederich, Angew. Chem. Int. Ed. 1999, 38, 1350-1377.

27. J. Liu, J. W. Y. Lam, B. Z. Tang, Chem. Rev. 2009, 109, 5799-5867.

28. S. Okada, S. Peng, W. Spevak, D. Charych, Acc. Chem. Res. 1998, 31, 229-239.

29. A. Ulman, Chem. Rev. 1996, 96, 1533-1554.

30. G. Wegner, Makromol. Chem. 1972, 154, 35-48.

31. G. Wegner, Z. Naturforsch. B: Anorg. Chem. Org. Chem. 1969, 24, 824-832.

32. B. Chu, R. Xu, Acc. Chem. Res. 1991, 24, 384-389.

33. R. W. Carpick, D. Y. Sasaki, M. S. Marcus, M. A. Eriksson, A. R. Burns, J. Phys.: Condens. Matter 2004, 16, R679-R697.

34. D. J. Ahn, J.-M. Kim, Acc. Chem. Res. 2008, 41, 805-816.

35. G. N. Patel, R. R. Chance, J. D. Witt, J. Chem. Phys. 1979, 70, 4387.

36. R. R. Chance, Macromolecules 1980, 13, 396-398.

37. A. J. Berlinsky, F. Wudl, K. C. Lim, C. R. Fincher, A. J. Heeger, J. Polym. Sci. Polym. Phys. Ed. 1984, 22, 847-852.

38. K. C. Lim, A. J. Heeger, J. Chem. Phys. 1985, $82,522-530$.

39. G. Wenz, M. A. Müller, M. Schmidt, G. Wegner, Macromolecules 1984, 17, 837850.

40. R. Giesa, R. C. Schulz, Polym. Int. 1994, 33, 43-60.

41. H. Müller, C. J. Eckhardt, Mol. Cryst. Liq. Cryst. 1978, 45, 313-318.

42. Y. Tomioka, N. Tanaka, S. Imazeki, J. Chem. Phys. 1989, 91, 5694-5700.

43. R. W. Carpick, D. Y. Sasaki, A. R. Burns, Langmuir 2000, 16, 1270-1278.

44. A. R. Burns, R. W. Carpick, D. Y. Sasaki, J. A. Shelnutt, R. Haddad, Tribol. Lett. 2001, 10,
89-96.

45. M. F. Rubner, Macromolecules 1986, 19, 2114-2128.

46. M. F. Rubner, Macromolecules 1986, 19, 2129-2138.

47. R. A. Nallicheri, M. F. Rubner, Macromolecules 1991, 24, 517-525.

48. H. Feng, J. Lu, J. Li, F. Tsow, E. Forzani, N. Tao, Adv. Mater. 2012, 25, 1729-1733.

49. D.-H. Park, J. Hong, I. S. Park, C. W. Lee, J.M. Kim, Adv. Funct. Mater. 2014, 24, 51865193.

50. K. Yoshino, K. Nakao, M. Onoda, R.-I. Sugimoto, Solid State Commun. 1988, 68, 513-516.

51. K. Yoshino, K. Nakao, M. Onoda, R.-I. Sugimoto, J. Phys.: Condens. Matter 1989, 1, 1009-1012.

52. B. C. Hess, G. S. Kanner, Z. Vardeny, Phys. Rev. B 1993, 47, 1407-1411.

53. E. J. Samuelsen, J. Mardalen, O. R. Konestabo, M. Hanfland, M. Lorenzen, Synth. Met. 1999, 101, 98-99.

54. T. Kaniowski, S. Niziol, J. Sanetra, M. Trznadel, A. Pron, Synth. Met. 1998, 94, 111-114.

55. Y. Muramatsu, T. Yamamoto, M. Hasegawa, T. Yagi, H. Koinuma, Polymer 2001, 42, 6673-6675.

56. D. Moses, A. Feldblum, E. Ehrenfreund, A. J. Heeger, T. C. Chung, A. G. MacDiarmid, Phys. Rev. B 1982, 26, 3361-3369.

57. A. Brillante, M. Hanfland, K. Syassen, J. Hocker, Physica B+C 1986, 139-140, 533536.

58. M. Hanfland, A. Brillante, K. Syassen, M. Stamm, J. Fink, J. Chem. Phys. 1989, 90, 1930-1934.

59. V. Morandi, M. Galli, F. Marabelli, D. Comoretto, Phys. Rev. B 2009, 79, 045202.

60. P. Fedorko, V. Skakalova, Synth. Met. 1998, 94, 279-283.

61. T. Yamamoto, Y. Muramatsu, B.-L. Lee, H. Kokubo, S. Sasaki, M. Hasegawa, T. Yagi, K. Kubota, Chem. Mater. 2003, 15, 4384-4393.

62. T. Shiga, A. Okada, H. Takahashi, T. Kurauchi, J. Mater. Sci. Lett. 1995, 14, 17541756. 
63. T. Shiga, T. Narita, K. Tachi, A. Okada, H. Takahashi, T. Kurauchi, Polym. Eng. Sci. 1997, 37, 24-30.

64. T. Shiga, T. Ikawa, A. Okada, J. Appl. Polym. Sci. 1998, 67, 259-266.

65. M. Kasha, H. R. Rawls, M. Ashraf ElBayoumi, Pure Appl. Chem. 1965, 11, 371392.

66. J. B. Birks, Rep. Prog. Phys. 1975, 38, 903974.

67. F. M. Winnik, Chem. Rev. 1993, 93, 587614.

68. F. Würthner, T. E. Kaiser, C. R. Saha-Möller, Angew. Chem. Int. Ed. 2011, 50, 3376-3410.

69. R. H. Friend, R. W. Gymer, Holmes, AB, J. H. Burroughes, R. N. Marks, C. Taliani, D. Bradley, D. A. Dos Santos, J. L. Brédas, M. Lögdlund, W. R. Salaneck, Nature 1999, 397, 121-128.

70. J. Luo, Z. Xie, J. W. Y. Lam, L. Cheng, B. Z. Tang, H. Chen, C. Qiu, H. S. Kwok, X. Zhan, Y. Liu, D. Zhu, Chem. Commun. 2001, 17401741.

71. R. Hu, J. W. Y. Lam, B. Z. Tang, In Aggregation-Induced Emission: Fundamentals and Applications, Chapter 12: AlE-Active Polymers; A. Qin, B. Z. Tang, Eds.; John Wiley and Sons Ltd: Chichester, United Kingdom, 2013 pp. 253-283.

72. Z. Zhao, S. Chen, J. W. Y. Lam, P. Lu, Y. Zhong, K. S. Wong, H. S. Kwok, B. Z. Tang, Chem. Commun. 2010, 46, 2221-2223.

73. X. Zhang, Z. Chi, J. Zhang, H. Li, B. Xu, X. Li, S. Liu, Y. Zhang, J. Xu, J. Phys. Chem. B 2011, 115, 7606-7611.

74. H. Li, Z. Chi, B. Xu, X. Zhang, X. Li, S. Liu, Y. Zhang, J. Xu, J. Mater. Chem. 2011, 21, 3760-3767.

75. J. Tong, Y. Wang, J. Mei, J. Wang, A. Qin, J. Z. Sun, B. Z. Tang, Chem. Eur. J. 2014, 20, 4661-4670.

76. J. R. Kumpfer, S. D. Taylor, W. B. Connick, S. J. Rowan, J. Mater. Chem. 2012, 22, 14196.

77. M. J. Robb, W. Li, R. C. R. Gergely, C. C. Matthews, S. R. White, N. R. Sottos, J. S. Moore, ACS Cent. Sci. 2016, 2, 598-603.

78. C. Lowe, C. Weder, Synthesis 2002, 11851190.

79. C. Lowe, C. Weder, Adv. Mater. 2002, 14,
$1625-1629$.

80. B. R. Crenshaw, C. Weder, Chem. Mater. 2003, 15, 4717-4724.

81. J. Kunzelman, B. R. Crenshaw, M. Kinami, C. Weder, Macromol. Rapid Commun. 2006 27, 1981-1987.

82. M. Kinami, B. R. Crenshaw, C. Weder, Chem. Mater. 2006, 18, 946-955.

83. A. Pucci, M. Bertoldo, S. Bronco, Macromol. Rapid Commun. 2005, 26, 1043-1048.

84. A. Pucci, F. Di Cuia, F. Signori, G. Ruggeri, J. Mater. Chem. 2007, 17, 783-790.

85. F. Donati, A. Pucci, C. Cappelli, B. Mennucci, G. Ruggeri, J. Phys. Chem. B 2008, 112, 3668-3679.

86. A. Pucci, F. Donati, G. Ruggeri, F. Ciardelli, ePolymers 2009, 9, 716-726.

87. B. R. Crenshaw, C. Weder, Macromolecules 2006, 39, 9581-9589.

88. N. A. A. Rossi, E. J. Duplock, J. Meegan, D. R. T. Roberts, J. J. Murphy, M. Patel, S. J. Holder, J. Mater. Chem. 2009, 19, 76747686.

89. F. Cellini, L. Block, J. Li, S. Khapli, S. D. Peterson, M. Porfiri, Sens. Actuator B-Chem. 2016, 234, 510-520.

90. D. L. Andrews, Chemical Physics 1989, 135, 195-201.

91. K. E. Sapsford, L. Berti, I. L. Medintz, Angew. Chem. Int. Ed. 2006, 45, 4562-4589.

92. S. Karthikeyan, R. P. Sijbesma, Macromolecules 2009, 42, 5175-5178.

93. A.-Y. Jee, M. Lee, Chem. Phys. Lett. 2011, 501, 287-291.

94. H. Staudinger, W. Heuer, Ber. dtsch. Chem. Ges. A/B 1934, 67, 1159-1164.

95. P. A. May, J. S. Moore, Chem. Soc. Rev. 2013, 42, 7497-7506.

96. C. Weder, Nature 2009, 459, 45-46.

97. D. A. Davis, A. Hamilton, J. Yang, L. D. Cremar, D. Van Gough, S. L. Potisek, M. T. Ong, P. V. Braun, T. J. Martínez, S. R. White, J. S. Moore, N. R. Sottos, Nature 2009, 459, 68-72.

98. R. Klajn, Chem. Soc. Rev. 2014, 43, 148-184.

99. S. Jiang, L. Zhang, T. Xie, Y. Lin, H. Zhang, Y. $\mathrm{Xu}$, W. Weng, L. Dai, ACS Macro Lett. 2013, 2, 705-709. 
100. G. Hong, H. Zhang, Y. Lin, Y. Chen, Y. Xu, W. Weng, H. Xia, Macromolecules 2013, 46, 8649-8656.

101. X. Fang, H. Zhang, Y. Chen, Y. Lin, Y. Xu, W. Weng, Macromolecules 2013, 46, 65666574.

102. Y. Chen, H. Zhang, X. Fang, Y. Lin, Y. Xu, W. Weng, ACS Macro Lett. 2014, 3, 141-145.

103. H. Zhang, Y. Chen, Y. Lin, X. Fang, Y. Xu, Y. Ruan, W. Weng, Macromolecules 2014, 47, 6783-6790.

104. G. R. Gossweiler, C. L. Brown, G. B. Hewage, E. Sapiro-Gheiler, W. J. Trautman, G. W. Welshofer, S. L. Craig, ACS Appl. Mater. Interfaces 2015, 7, 22431-22435.

105. H. Zhang, F. Gao, X. Cao, Y. Li, Y. Xu, W. Weng, R. Boulatov, Angew. Chem. Int. Ed. 2016, 55, 3040-3044.

106. Z. Wang, Z. Ma, Y. Wang, Z. Xu, Y. Luo, Y. Wei, X. Jia, Adv. Mater. 2015, 27, 64696474.

107. R. Göstl, R. P. Sijbesma, Chem. Sci. 2016, 7, 370-375.

108. Z. Li, R. Toivola, F. Ding, J. Yang, P.-N. Lai, T. Howie, G. Georgeson, S.-H. Jang, X. Li, B. D. Flinn, A. K. Y. Jen, Adv. Mater. 2016, 28, 6592-6597.

109. S.-Y. Cho, J.-G. Kim, C.-M. Chung, Sens. Actuator B-Chem. 2008, 134, 822-825.

110. Y.-K. Song, K.-H. Lee, W.-S. Hong, S.-Y. Cho, H.-C. Yu, C.-M. Chung, J. Mater. Chem. 2012, 22, 1380-1386.

111. K. Imato, A. Irie, T. Kosuge, T. Ohishi, M. Nishihara, A. Takahara, H. Otsuka, Angew. Chem. Int. Ed. 201554 6168-6172.

112. K. Imato, T. Kanehara, T. Ohishi, M. Nishihara, H. Yajima, M. Ito, A. Takahara, H. Otsuka, ACS Macro Lett. 2015, 4, 13071311.

113. K. Imato, T. Kanehara, S. Nojima, T. Ohishi, Y. Higaki, A. Takahara, H. Otsuka, Chem. Commun. 2016, 52, 10482-10485.

114. Y. Chen, A. J. H. Spiering, S. Karthikeyan, G. W. M. Peters, E. W. Meijer, R. P. Sijbesma, Nature Chem. 2012, 4, 559-562.

115. Y. Chen, R. P. Sijbesma, Macromolecules 2014, 47, 3797-3805.

116. J. M. Clough, C. Creton, S. L. Craig, R. P. Sijbesma, Adv. Funct. Mater. 2016, DOI 10.1002/adfm. 201602490

117. P. G. Gillespie, R. G. Walker, Nature 2001, 413, 194-202.

118. V. Vogel, M. Sheetz, Nature Rev. Mol. Cell. Biol. 2006, 7, 265-275.

119. B. Geiger, J. P. Spatz, A. D. Bershadsky, Nature Rev. Mol. Cell. Biol. 2009, 10, 21-33.

120. N. Bruns, K. Pustelny, L. M. Bergeron, T. A. Whitehead, D. S. Clark, Angew. Chem. Int. Ed. 2009, 48, 5666-5669.

121. K. Makyła, C. Müller, S. Lörcher, T. Winkler, M. G. Nussbaumer, M. Eder, N. Bruns, Adv. Mater. 2013, 25, 2701-2706.

122. J. Longo, C. Yao, C. Rios, N. T. T. Chau, F. Boulmedais, J. Hemmerle, P. Lavalle, S. M. Schiller, P. Schaaf, L. Jierry, Chem. Commun. 2015, 51, 232-235.

123. J. N. Brantley, C. B. Bailey, J. R. Cannon, K. A. Clark, D. A. Vanden Bout, J. S. Brodbelt, A. T. Keatinge-Clay, C. W. Bielawski, Angew. Chem. Int. Ed. 2014, 53, 5088-5092.

124. W. Weng, J. B. Beck, A. M. Jamieson, S. J. Rowan, J. Am. Chem. Soc. 2006, 128, 11663-11672.

125. D. W. R. Balkenende, S. Coulibaly, S. Balog, Y. C. Simon, G. L. Fiore, C. Weder, J. Am. Chem. Soc. 2014, 136, 10493-10498.

126. P. Chen, Q. Li, S. Grindy, N. HoltenAndersen, J. Am. Chem. Soc. 2015, 137, 11590-11593.

127. A. Lavrenova, J. Farkas, C. Weder, Y. C. Simon, ACS Appl. Mater. Interfaces 2015, 7, 21828-21834. 


\section{Céline Calvino}

Céline Calvino is currently a PhD student in Prof. Christoph Weder's research group at the Adolphe Merkle Institute of the University of Fribourg, Switzerland. She graduated from the University Fribourg in 2014, with a focus on organic synthesis, polymer chemistry, and surface science. Her ongoing research focuses on the synthesis of mechanochromic polymers based on non-covalent interactions.

\section{Laura Neumann}

Laura Neumann is currently a PhD student in Prof. Christoph Weder's research group at the Adolphe Merkle Institute of the University of Fribourg, Switzerland. She graduated from the Eindhoven University of Technology in 2015, with a focus on supramolecular chemistry. Her ongoing research focuses on the synthesis and characterization of mechanoresponsive supramolecular polymers

\section{Christoph Weder}

Prof. Christoph Weder is Director of the Adolphe Merkle Institute (AMI) at the University of Fribourg and leads the Swiss National Center of Competence in Research Bio-Inspired Materials. Chris was educated at ETH Zurich and held positions at the Massachusetts Institute of Technology, ETH Zurich, and Case Western Reserve University, before joining the AMI as Professor for Polymer Chemistry and Materials in 2009. His research interests include the design, synthesis and investigation of stimuliresponsive polymers and nanomaterials.

\section{Stephen Schrettl}

Dr. Stephen Schrettl is a postdoctoral researcher with Prof. Christoph Weder at the Adolphe Merkle Institute in Fribourg, Switzerland. He received his Chemistry degree from Freie Universität Berlin in 2009 and his PhD in Materials Science from the Ecole Polytechnique Fédérale de Lausanne (EPFL) in 2014. After continuing as a postdoctoral researcher at EPFL, he joined the Adolphe Merkle Institute in 2015 to investigate mechanically responsive materials. 


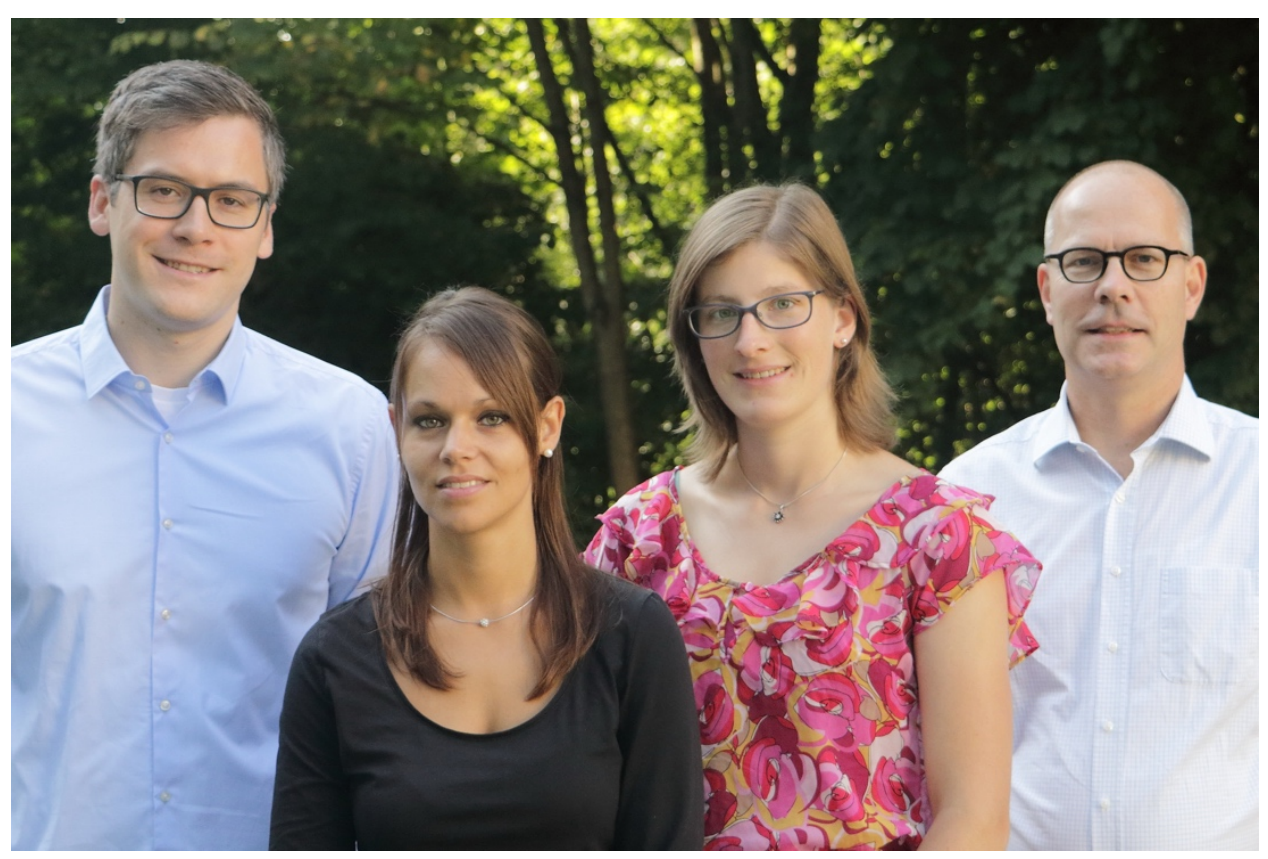

Group photo of the authors. From left: Stephen Schrettl, Céline Calvino, Laura Neumann, and Christoph Weder. If preferred, individual images can be provided instead. 
GRAPHICAL ABSTRACT

\section{Céline Calvino", Laura Neumann", Christoph Weder*, Stephen Schrettl*}

\section{Approaches to Polymeric Mechanochromic Materials}

Mechanochromic materials display a change of their optical properties upon mechanical deformation. Such materials are of interest for technological applications as well as fundamental research and can aid in the identification of processes that lead to mechanical failure in polymeric objects. In this highlight, approaches toward polymeric materials that signal mechanical stresses through a chromic response are discussed. These responses almost exclusively originate from changes of molecular structure, conformational rearrangements, or disruption of intermolecular interactions.

\section{mechanical stimulus}

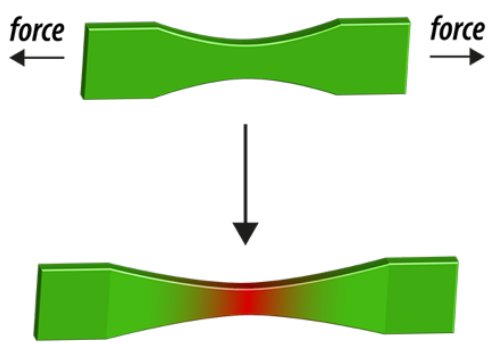

chromic response 